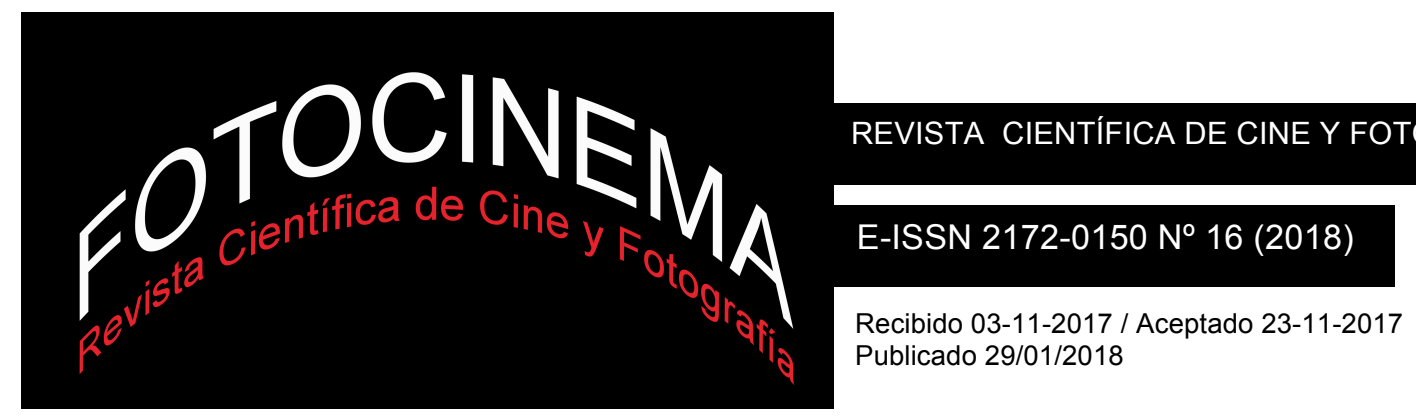

\title{
LA INFLUENCIA PICTÓRICA EN LA REPRESENTACIÓN ESPACIAL DEL CINE DE LOS ORÍGENES. LA RELACIÓN CAMPO-FUERA DE CAMPO DESDE EL CINE DE GEORGES MÉLIÈS
}

\section{THE INFLUENCE OF PAINTING IN THE EARLY CINEMA'S SPACE. THE RELATIONSHIP BETWEEN SCREEN AND OFF-SCREEN IN GEORGES MÉLIÈS}

\author{
Susana Palés \\ Universitat Politècnica de València, España \\ paleschaveli@gmail.com
}

\section{Resumen:}

La influencia de la pintura sobre la imagen cinematográfica ha sido constante desde la aparición del cine hasta nuestros días. Esta influencia fue sin duda mucho más notable durante el cine de los orígenes, donde la construcción espacial se encontraba totalmente anclada a la concepción de cuadro, limitando las posibilidades del medio y convirtiendo el espacio en uno totalmente limitado y estático. A pesar de la herencia pictórica, durante los primeros años del cine hubo un uso generalizado del fuera de campo que, aún siendo todavía bastante limitado en cuanto a sus posibilidades, comenzó a abrir los límites de la pantalla anticipando el espacio ilimitado que caracterizará el cine en los años posteriores. Georges Méliès funcionará como mejor exponente de la concepción del film como cuadro donde, sin embargo, las llamadas al espacio más allá se utilizarán también de forma constante anticipando el dinamismo propio del espacio en el cine moderno.

\begin{abstract}
:
The influence of painting in the cinematographic image has been constant since the apparition of cinema until our days. This influence was, undoubtedly, more evident in early cinema, where the conception of space was absolutely linked with the idea of a painting, limiting the films' posibilities and making their space limited and static. Although this pictorical heritage, during the first years of cinema, the use of the offscreen was generalized and, inspite of the limited posibilities of this early off-screen, it started to open the limits of the screen, anticipating the unlimited space in modern cinema. Georges Méliès was the best example of the idea of the film as a painting, but, also, used the off-screen so often, that he became one of the pioneers in the use of the absent space, anticipating the dinamism of modern cinema.
\end{abstract}

\section{Palabras clave:}

Cine y pintura; espacio; fuera de campo; cine de los orígenes; Georges Méliès

Keywords:

Cinema and Painting; Space; Off-screen; Early Cinema; Georges Méliès 
Cómo citar: Palés, S., La influencia pictórica en la representación espacial del cine de los orígenes. La relación campo-fuera de campo desde el cine de Georges Méliès. Fotocinema. Revista científica de cine y fotografía, n ${ }^{0}$ 16, pp. 15-33.

Disponible: http://www.revistas.uma.es/index.php/fotocinema/

DOI: http://dx.doi.org/10.24310/Fotocinema.2017.voi15

\section{Introducción. Cine y pintura}

Desde la primera proyección de La sortie des usines Lumière en 1985, muchas han sido las reflexiones que se han suscitado en torno a la relación entre cine y pintura, y muchas han sido las aportaciones que se han generado desde ambas disciplinas. Cuando los hermanos Lumière presentaron su cinematógrafo al mundo comenzó un diálogo que se ha mantenido de forma constante: cuadros vivientes - La marquesa de o (Die Marquise von O, Éric Rohmer, 1976), Los Sueños (Dreams, Akira Kurosawa,1990), El molino y la cruz (Mlyn I Krzyz, Lech Majewsi, 2011)...- pintores-cineastas -Edward Hopper- o cineastaspintores -Yasujiro Ozu, Robert Bresson, Michelanchelo Antonioni....1-. Si hubiera que subrayar un primer punto en común, sin duda habría que destacar la herencia pictórica que se mantuvo rígidamente anclada a las primeras producciones cinematográficas, convirtiendo los films de esta época en algo parecido a cuadros vivientes, donde las posibilidades que ofrecía la cámara estaban aún muy lejos de ser totalmente agotadas. En un momento en el que el espacio pictórico se había liberado gracias al relevo de la fotografía ${ }^{2}$, el cine se instaura como el nuevo lugar donde los códigos visuales establecidos durante el Renacimiento se verán de nuevo perpetuados a través de la pantalla.

En las próximas líneas realizaremos una reflexión sobre este aspecto de la relación cine-pintura, en el que pondremos el punto de atención en la obra de

1 Todos estos ejemplos suponen solo una selección de entre otros muchos que podrían tomarse tanto en el ámbito del cine como en el de la pintura.

2 La fotografía fue inventada en el momento en que, especialmente con Turner, la pintura "cambia de espacio", o, en palabras de Francastel, deja de dar al mecenas "la vista de una parte de la tierra por dominar". Esta dimensión "propietaria" del sistema de representación del espacio surgido del Quattrocento es incontestablemente sustituida por la fotografía durante toda la segunda mitad del "siglo burgués". (Burch, 2016, pp. 23-24) 
Georges Méliès debido a la férrea fidelidad que mantuvo ante ciertos cánones compositivos propios de la pintura, incluso cuando el cine ya había comenzado a desligarse de ellos. A lo largo de esta reflexión defenderemos no sólo la estrecha relación entre la composición pictórica renacentista y el cine de los orígenes, sino también la existencia de un fuera de campo que, aún siendo todavía muy limitado, será un elemento constante en las obras de este primer periodo. Otro de nuestros objetivos es reafirmar la figura de Méliès como elemento clave en estos primeros años del cine, ya no como pionero de los efectos especiales o paladín del cine narrativo, sino como una figura dual que demuestra ser también defensor de una tradición escénica anclada en el siglo XIX. Con todo esto pretendemos defender la existencia de un cine de los orígenes con una construcción espacial esencialmente pictórica que, sin embargo, resultará mucho más propenso a la activación del espacio ausente que las películas desarrolladas dentro del marco del Método de Representación Institucional y el posterior cine clásico. Para desarrollar estos objetivos nos valdremos de estudios sobre el espacio, la imagen cinematográfica y la herencia pictórica en el cine realizados por Noël Burch, Jacques Aumont o Francisco Gómez Tarín, superponiéndolos y analizándolos desde la propia producción cinematográfica de George Méliès.

La comparación del espacio cinematográfico con la representación espacial desarrollada durante el Renacimiento, ha suscitado la aparición de dos tesis antagónicas que se postulan sobre esta posible relación. La primera, enunciada por Marcelin Pleynet y defendida y matizada por Jean-Louis Baudry, identifica el aparato cinematográfico como puramente ideológico con un código perspectivo directamente heredado de la perspectiva científica del Quattrocento. Por otro lado, las investigaciones de Jean Patrick Lebel y Jean Mitry que señalan el aparato cinematográfico como ideológicamente neutro, reproductor de la percepción ocular natural. Aunque, como bien señala Pascal Bonitzer, la cuestión ya haya envejecido, "remite a un problema que el cine no cesa de plantearse, el de la producción de las imágenes en su vínculo con lo real" (Bonitzer, 2007, p.11). Nos parece, en cualquier caso, muy potente la conclusión a la que llega Bonitzer al señalar un lugar común para ambas tesis: 
[...] Del supuesto según el cual la cámara produciría un código perspectivo heredado del Quattrocento no se deduce necesariamente que no establece ninguna relación objetiva con lo real; por el contrario, si la perspectiva del Quattrocento puede ser llamada científica (...) se debe a que ésta matematiza las condiciones de la percepción ocular y, por lo tanto, asigna un estatuto parcialmente objetivo a la representación. (2007, p.12)

Conviene aclarar, no obstante, que las relaciones entre el cine de los orígenes y la pintura aquí planteados, no se centran tanto en la posible objetividad del aparato cinematográfico, sino en las cuestiones de índole compositivo y espacial que relacionan ambas disciplinas a través la disposición de los elementos en la imagen, la construcción del espacio o la iluminación.

\section{El Método de Representación Primitivo}

Con los primeros films de Lumière comenzó la construcción del vocabulario cinematográfico y la asimilación por parte de los espectadores de sus códigos visuales, cuyos cimentos se alzaban sobre aquellos propios de artes como la pintura, el teatro y la fotografía. Aunque, por supuesto, existen algunas excepciones -entre las que, paradójicamente, se encontrará la producción Lumière- las películas realizadas durante estas primeras décadas presentan una construcción espacial heredera del cuadro renacentista. Este modo de representación fue denominado por Noël Burch (Burch, 2016) como Método de Representación Primitivo (o MRP) y supone el modo de representación común hasta la implantación del Método de Representación Institucional (MRI) hacia 1915², que coincidiría con los cánones establecidos en el cine clásico y perpetuados, en varios aspectos, hasta nuestros días. Nos gustaría señalar, no obstante, que estos dos métodos no se han sucedido de forma inmediata y ordenada y es posible observar trazos propios de uno y otro dentro de los mismos films durante una larga época de transición. George Méliès será el ejemplo perfecto para ilustrar este cambio gradual que no abarcó a todos los

$3 \mathrm{El}$ asentamiento del Método de Representación Institucional suele fijarse a partir del film El nacimiento de una nación (The birth of a nation, D.W. Griffith, 1915). 
cineastas, permitiendo la convivencia de films propios del MRP con aquellos que ya se encontraban mucho más cerca de lo que vendría a constituir el cine clásico. Es erróneo, por tanto, concebir el paso de uno a otro como una evolución, ya que se trata más bien de la consolidación de un método de representación totalmente diferente que coexistirá durante décadas con el primero.

Centrando la vista en este Método de Representación Primitivo y en su estrecha relación con los métodos compositivos pictóricos, analizaremos una serie de características comunes en los films de este periodo. Es importante insistir en que esta herencia pictórica parece tomar dos vertientes bien definidas que dividen el cine de este periodo en cine documental (con los hermanos Lumière como pioneros) y el cine narrativo o de ficción. Ambas vertientes convivirán a lo largo de este periodo, presentando una relación con los métodos compositivos pictóricos que será muy diferente en cada una de ellas.

A pesar de que defendemos una doble influencia pictórica en las dos vertientes cinematográficas de este primer periodo, es necesario indicar que, en muchas ocasiones, se ha señalado una tradición teatral por encima de la pictórica en el cine narrativo, especialmente en el desarrollado por Georges Méliès:

Sabemos que la herencia de los primeros films está -desde un punto de vista genérico- en la pintura y en el teatro. (...) Esta doble herencia produce un punto de inflexión puesto que, indudablemente, la formación de los Lumière es más cercana a la pintura y la de Méliès, al teatro. (Gómez Tarín, 2006, p.85)

En cualquier caso, y aunque, debido a su formación, la influencia del teatro en Méliès es más que evidente, no hay que pasar por alto que la puesta en escena teatral le debe mucho a la tradición pictórica, por lo que mantendremos el apelativo pictórico también para su producción cinematográfica.

Una de las características más significativas del cine del MRP, común tanto al cine narrativo como al documental, será la utilización de la cámara fija. Durante el tiempo en el que se desarrolló este método de representación no se aprovechaban todas las posibilidades que ofrecía el movimiento intrínseco del cine y la cámara, sin escapar a estas primeras limitaciones, se disponía 
generalmente de forma frontal en la escena -a excepción de algunas películas de cine documental donde sí será común un ligero descentramiento del objetivo- sin ninguna posibilidad de movimiento. El encuadre, por tanto, no se renovaba, por lo que las características del espacio cinematográfico se convertían prácticamente en las mismas que pudiera ofrecer la pintura o el teatro. Habrá que esperar años hasta que la cámara comience a liberarse de su yugo moviéndose libremente por el espacio. La introducción de travellings, panorámicas y zooms, sumadas a la introducción del montaje y los raccords, convertirán progresivamente el espacio cinematográfico en uno amplio, dinámico y homogéneo.

Otro rasgo común a las películas del MRP será la autarquía del cuadro, mediante la cual cada escena suele ser autoconclusiva, comenzando y terminando en un mismo plano. Incluso con la incorporación de distintas escenas en el periodo de 1902 a 1910 gracias a la primera introducción del montaje-que, en el caso de Méliès, se producirá por primera vez en La Cenicienta (Cendrillon, Georges Méliès, 1899)- las acciones siguen siendo autoconclusivas, mostrando así varios cuadros que, aun estando conectados a través de la acción, no muestran ningún signo de continuidad espacial. Las películas se convertirán en rígidos cuadros vivientes con una relación espacial entre escenas puramente teatral. De esta forma, la representación no realiza una búsqueda de la impresión de realidad y el espacio no será realmente un espacio habitable para el espectador. La inmovilidad de la cámara, la autarquía del cuadro y la posición centralizada del objetivo convertirán la mirada del espectador en una propia del espectador teatral, incapaz de penetrar en la acción traspasando el proscenio, marcada por una exterioridad difícil de superar, que impedirá la identificación con ningún personaje y anclará al espectador en la posición de la butaca.

El espacio resultante de estas características será un espacio estático, poco verosímil y con una discontinuidad espacial entre escenas que lo convierten en un espacio fragmentado e inhabitable. La posterior introducción de los raccords (a partir de 1910) ayudará a enlazar las distintas escenas convirtiendo 
paulatinamente el espacio cinematográfico en uno homogéneo, dinámico y prácticamente ilimitado. El uso de planos de detalle y primeros planos -que al principio resultarán monstruosos- ayudarán también a abrir los límites del encuadre alejándose de la rígida concepción del cuadro pictórico para adentrarse en una nueva forma de representación puramente cinematográfica.

\section{El cine documental y su relación con la pintura impresionista}

El género documental presenta unas características propias que lo distinguirán del cine narrativo. Este cine parece nacer desde la concepción del cine como innovación científica, donde una la búsqueda de documentar y "atrapar" un instante de realidad acompañará gran parte de estas obras y es que muchos concibieron originalmente el cine como una herramienta de observación más que como un nuevo arte. Entre las películas inscritas dentro de esta corriente encontramos una falta de puesta en escena generalizada. El hecho de seleccionar el punto de vista desde el que captar las imágenes, pero sin componer los elementos de la escena, acerca este tipo de films a los paisajes impresionistas -basta comparar L'arrivée d'un train en gare (Louis Lumière,1895) con el cuadro Tren en la nieve (Monet,1875) para comprobar que las composiciones resultantes eran, en muchas ocasiones, bastante parecidas-. Es importante subrayar, en cualquier caso, que no debemos enlazar necesariamente los films filmados en exteriores con este primer cine documental, ya que es posible encontrar puesta en escena aunque la película no haya sido rodada dentro de un estudio. Para ilustrar esto y mostrar, además, que los primeros cineastas no llevaban necesariamente una línea temática estricta, tenemos el ejemplo de El regador regado (L'arroseur arrossé, Lumière, 1895), que supone uno de los pocos films narrativos dentro de la creación Lumière con una puesta en escena realizada en un exterior. Curiosamente encontramos un ejemplo diametralmente opuesto entre la producción de Méliès con Paisaje desde el tren (Panorama pris d'un train en marche, Georges Méliès, 1898), único atisbo de cine documental entre su extensa producción de films narrativos con una puesta de escena especialmente elaborada. 
Noël Burch resume así el modo de componer del cine documental:

[...]Estas películas y todos los demás "cuadros-documento" que participan en la construcción del modelo Lumière me parece que en última instancia revelan una idéntica dirección: escoger un encuadre tan apto como sea posible para "atrapar" un instante de realidad, y filmarlo luego sin ninguna preocupación de controlar ni de centrar la acción. (Burch, 2016, pp.36-37).

Y es que, como el propio Louis Lumière afirmó al final de su vida: "[...] mis trabajos fueron trabajos de investigación técnica. Jamás hice lo que se llama puesta en escena" (Sadoul, Louis Lumière, p.107).

\section{Cine narrativo. La herencia del cuadro renacentista en la puesta en escena}

En oposición al cine documental encontramos lo que se denominará cine narrativo, que se alzó como el modelo imperante durante las primeras décadas. Este cine se caracterizará por incorporar métodos narrativos propios de la literatura, la pintura y el teatro.

En el cine narrativo, no bastaba con capturar un momento a través de la cámara, sino que era necesario componer y crear ese momento a través de un guion (con mayor o menor elaboración) y una puesta en escena que lo acercará a la pintura del Quattrocento y también a muchos recursos propios del teatro a la italiana.

Si algo distingue y confronta el cine narrativo y el documental es, por tanto, la forma de interactuar y ordenar los elementos del entorno a la hora de crear y componer las imágenes. En el caso del cine narrativo, su método compositivo recuerda a la pintura realizada en el taller (en contraposición a la realizada por los paisajistas impresionistas) con una puesta en escena elaborada y estudiada. De tal forma, podríamos enfrentar el documental de influencia impresionista frente al cine narrativo cuya influencia se encuentra en los métodos compositivos desarrollados durante el Quattrocento. 
La puesta en escena que caracterizará al cine narrativo presentará unos elementos comunes en prácticamente todas las producciones, elementos que acompañarán la producción completa de Méliès hasta su último film producido en 1913. La colocación de la cámara en una posición privilegiada y central respecto a la acción será una constante en todas estas obras. El encuadre presenta un plano general donde el objetivo, que actuará como único punto de fuga, ofrece unas composiciones en estrecha relación con la perspectiva artificialis desarrollada durante el Quattrocento. La colocación de los actores en este espacio también es muy concreta, privilegiando el espacio central como el más idóneo para la acción y mostrándolos siempre de cuerpo entero, evitando su fragmentación tanto por los bordes de la pantalla como a través de la utilización de primeros planos o planos de detalle. A pesar de esta tendencia por centralizar la acción, en el cine de los orígenes los actores se moverán con cierta libertad por el espacio, y sus entradas y salidas de campo por los extremos serán muy habituales. Estas entradas y salidas tendrán un efecto muy teatral debido a que la cámara no seguirá a los actores tras abandonar el encuadre, sino que se mantendrá fija en la escena, incapaz de mostrar el fuera de campo al cual se ha marchado el personaje -a excepción de las películas de múltiple escena, en la que es posible ver al personaje aparecer en un nuevo escenario-.

La utilización de decorados pintados es otro de los factores que relacionan directamente el cine con la representación pictórica. Este elemento, cuya función será abrir los límites de la representación y ampliar el espacio de forma significativa recordará, en muchas ocasiones, a las tempranas tentativas perspectivas de pintores como Giotto o Duccio. Es interesante observar como los inicios de la representación naturalista en la pintura aparecen, precisamente, ligados a la construcción de las primeras escenografías en Grecia y Roma, por lo que la utilización de la pintura como elemento de ilusión y ampliación espacial es prácticamente tan antigua como la propia representación naturalista.

En cuanto a la iluminación utilizada durante este primer periodo, encontramos una tendencia generalizada hacia una iluminación plana y homogénea que 
bañaba por igual toda la escena, dotándola de un aspecto muy parecido a los cuadros realizados durante el Trecento y el Quattrocento.

La herencia pictórica en el cine de los orígenes tiene distintas vertientes: por un lado, la compositiva (la disposición de los elementos en el plano, el punto de vista de la cámara...) y, por otro, encontramos la incorporación de la propia pintura para la creación del espacio (a través de los decorados pintados). Aunque a lo largo de la historia del cine irán sumándose otro tipo de recursos relacionados con la pintura (los tableaux vivant, la recreación de la plasticidad de algún pintor a través de la luz y el color...), podemos considerar que la relación cine-pintura era mucho más estrecha en los orígenes del cine debido a que muchos de los recursos que hemos considerado como pictóricos no se utilizaban como una forma de alusión a la pintura, sino que formaban la base sobre la que se construyeron los primeros códigos visuales cinematográficos

\section{Las consecuencias del espacio no renovable. Las relaciones entre campo y fuera de campo en el cine de los orígenes}

La influencia del cuadro pictórico en el uso de la cámara fija será uno de los factores más determinantes a la hora de establecer las características del espacio cinematográfico durante el periodo inicial del cine de los orígenes, afectando de forma directa a las relaciones que establece la imagen cinematográfica con su fuera de campo4. Después de observar cómo se construye el espacio en los films de este periodo, parece esencial analizar cómo se relacionan lo presente y lo ausente en estas imágenes para comprender hasta qué punto este espacio es más cercano a la pintura que al cine actual.

Si queremos estudiar las características de una representación espacial debemos observar qué relaciones se establecen entre su campo y su fuera de campo. Toda representación espacial bidimensional supone la existencia de estos dos espacios determinados por los límites de la imagen. Todos los 
elementos que la componen (ya sean personajes, objetos, elementos arquitectónicos...) formarán el campo. Frente a éste, de carácter visible y (cuasi) tangible, encontramos aquel que, aun manteniéndose oculto, formará parte indispensable del espacio representado. Este espacio, al que denominamos fuera de campo, estará formado por todo aquello más allá de los límites de la representación cuya existencia se insinúa desde la propia imagen. Campo y fuera de campo serán parte de un continuum espacial sobre el que se construirá la diégesis espacial. Hay que tener en cuenta, no obstante, que para que una representación espacial posea un fuera de campo, el espectador debe trascender dicha representación y considerar el cuadro -o la pantalla- como una ventana abierta al mundo, como el recorte de una realidad más extensa que no termina en los bordes de la pantalla.

En cualquier caso, aunque es posible concebir este espacio más allá en cualquier representación espacial -como afirmaba Gilles Deleuze, "siempre hay fuera de campo, incluso en la imagen más cerrada" (Deleuze, 1984, p.35)- para que el espectador repare en él y sea capaz de enlazarlo con lo que muestra la imagen, el fuera de campo ha de ser activado desde la misma. Estas llamadas desde la imagen hacia sus límites pueden ser de naturaleza muy variada distinguiéndose de carácter visual, sonoro y narrativo- y ayudan a crear un diálogo constante entre lo presente y lo ausente en la imagen. Centraremos la atención en las llamadas de carácter visual, por ser las únicas comunes al fuera de campo pictórico y cinematográfico y por tratarse, también, de las más utilizadas en el cine del MRP hasta la posterior aparición del sonoro y de una mayor elaboración narrativa.

El fuera de campo visual será, pues, aquel que, mediante recursos estrictamente visuales pondrá el punto de atención en el espacio ausente. Dentro de este podríamos distinguir entre interpelaciones, presencias parciales, espejos, sombras, entradas y salidas de campo y reencuadres. 5 Recurriremos a la obra de Georges Méliès -además de algún otro film destacable en cuanto a las relaciones presente-ausente- para ilustrar mejor estos ejemplos, utilizándolo

5 Debemos estas distinciones a trabajos como los de Philippe Durand (Durand, 1993), Noël Burch (Burch, 2008) o Francisco Gómez Tarín (2006) 
como el mejor exponente de los primeros films-cuadros. Será la férrea relación que mantendrá el autor con la tradición escénica del siglo XIX la que convertirá a Méliès en el mejor ejemplo de esta relación cine-pintura que, inevitablemente, le mantendrá anclado a una construcción espacial que pronto entrará en declive.

Centrando la vista en las distintas tipologías del fuera de campo visual, encontramos las interpelaciones, que consisten en gestos o miradas realizadas desde la imagen hacia los límites de ésta. Es muy frecuente encontrar este tipo de llamadas desde los primeros años del cine y su presencia, aunque menos habitual, aparece también en el ámbito pictórico -con obras como Judith y su sirvienta (Artemisa Gentileschi,1614)-. En La partida de naipes (Une partie de cartes, Georges Méliès, 1896), primer film de Méliès, encontramos una interpelación realizada por el personaje central que, llamando a alguien que se encuentra fuera de campo, provoca la aparición de la niña por el margen derecho de la imagen. Encontramos también una fórmula semejante en $L a$ Cenicienta cuando una multitud señala y saluda hacia el fuera de campo anticipando la aparición del cortejo real por el borde de la pantalla (F1, F2).

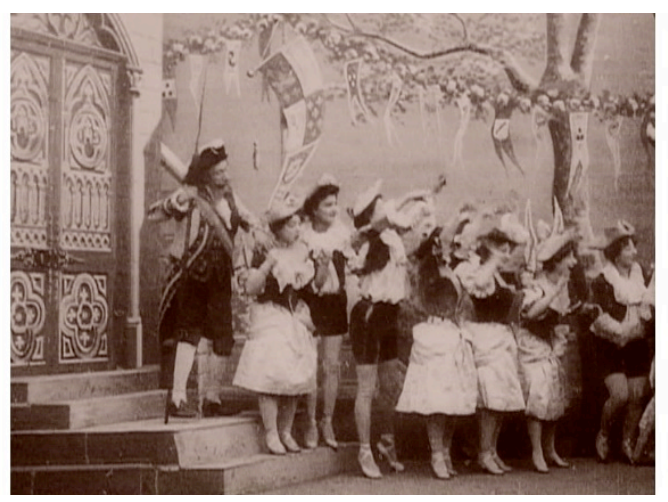

F1

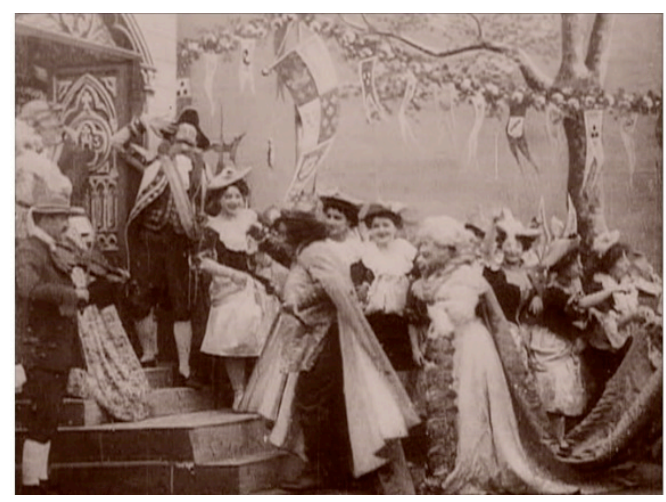

F2

Estas interpelaciones aparecen también en la curiosa obra La caja mágica (La boite a Malice, Georges Mèliés, 1903), donde el mago realiza llamadas hacia los bordes de la imagen por los que aparecen, obedientemente, una serie de objetos. Lo singular de este film reside en la activación del borde superior de la imagen, hacia el que también se realizan estas llamadas, desplazando así 
momentáneamente la atención del espectador hacia el espacio fuera de campo situado sobre el límite superior.

Durante el Método de Representación Primitivo, también será muy habitual realizar interpelaciones directas al espectador con miradas dirigidas directamente a cámara. Este tipo de gestos, que buscan la complicidad del espectador, son una herencia directa del teatro, donde eran muy habituales. Sin embargo, en el posterior desarrollo del MRI este tipo de llamadas se eliminarán por completo, y habrá que esperar hasta el cine moderno para encontrar de nuevo estos intentos de romper la cuarta pared. Un ejemplo de este recurso podemos encontrarlo en Mary Jane's mishap (George Albert Smith, 1903) aunque sin duda mucho más destacable será su presencia en la mayoría de las obras de Méliès que, concebidas como espectáculos ilusionistas, mostrarán al cineasta que, asumiendo el papel de mago, se dirigirá continuamente al público situado tras la cámara.

Las presencias parciales son otra forma sutil de activar el espacio más allá consistente en mostrar objetos o individuos recortados por los bordes de la imagen. De esta forma, el espectador reconstruirá aquello que se muestra sólo parcialmente imaginando lo que completa la imagen fuera de campo. Este recurso no será muy habitual en el cine de los orígenes donde, por influencia de la pintura clásica, los elementos se dispondrán preferiblemente en el centro de la composición en un plano general asegurando así una visión privilegiada del conjunto. Pese a todo, podemos encontrar ejemplos de este recurso que irá haciéndose más común conforme avanza la historia de la pintura y del cine. En el ámbito pictórico, encontramos un ejemplo especialmente prematuro e insólito en la obra El beato Ranieri libera a los pobres de una prisión de Florencia (Stefano di Giovanni Sasseta, 1444), inscrita dentro del periodo Gótico. La composición, muy poco convencional, sitúa a los personajes en el margen izquierdo del cuadro, recortándolos de forma abrupta. Entre la extensa producción de Méliès, resulta complicado encontrar ejemplos notables de presencias parciales debido a la férrea fidelidad que mantiene con el modelo de cuadro renacentista y también, especialmente, con el teatro, donde este tipo de 
recursos serán prácticamente inconcebibles. Aunque entre la producción de este primer periodo sí que aparecerán las presencias parciales, su utilización no será totalmente generalizada hasta la introducción de primeros planos o planos de detalle a través del montaje ${ }^{6}$. Sin embargo, la introducción de estos recursos no será sencilla, y al principio, esta fragmentación espacial será concebida como antinatural:

El montaje, el cambio de plano, el cambio brusco en general en el cine, ha sido una de las mayores violencias cometidas nunca contra la percepción "natural". Nada en nuestro entorno modifica nunca todas sus características tan total y tan bruscamente como la imagen fílmica, y nada en los espectáculos preexistentes al cine los había preparado para semejante brutalidad. Se comprende que haya provocado gritos. (Aumont, 1997, p.74)

La utilización de espejos para mostrar una parte del fuera de campo también ayuda a expandir de una forma muy sutil los límites de la imagen, asegurando la continuación del espacio más allá de ellos. Este recurso es especialmente habitual en el ámbito pictórico, especialmente en la pintura flamenca con obras como El matrimonio Arnolfini (Jan Van Eyck, 1434), aunque quizá el ejemplo más notable sea Las meninas (Velázquez, 1656) donde un pequeño espejo situado en la pared nos muestra el espacio fuera de campo que correspondería a la situación espacial del espectador. Esta utilización de los espejos es también habitual en el cine y, sin embargo, durante el cine de los orígenes resulta arduo encontrar ejemplos, especialmente entre la extensa producción de Méliès en la que no utilizaba ese recurso en ningún film.

Algo parecido ocurre con las sombras, otra forma de activación del espacio ausente siempre y cuando no se muestre la fuente emisora. Este uso de las sombras también es poco habitual en el cine de los orígenes, y habrá que esperar casi una década para que se generalice su uso con ejemplos tan

6 La utilización del primer plano en las películas de Méliès muestra una aparición temprana con El hombre de la cabeza de goma (L'homme a la tete en cahoutchouc, George Méliès, 1901) aunque este ejemplo -como el resto utilizados por el autor- lejos de fragmentar el espacio, funcionará como un truco más dentro de los sus característicos efectos, utilizado, en este caso, para expresar enormidad (y no como aproximación de la mirada). 
celebrados como el de Nosferatu (Murnau,1922) o la sombra sobre del asesino en $M$, el vampiro de Düsseldorf (M, Fritz Lang,1931).

Con las entradas y salidas de campo se establece una de las formas más eficaces y utilizadas para activar el espacio fuera de campo. A propósito de éstas, Noël Burch planteó que:

Una salida que deja un campo vacío atrae nuestro espíritu hacia un trozo determinado del espacio-fuera-de-campo (...) en un plano que empieza por un campo vacío (...) desde que el personaje entra efectivamente en campo esta entrada propone retrospectivamente a nuestro espíritu la existencia del segmento de espacio del que ha surgido. (Burch 2008, p. 28)

Nos encontramos ante la primera categoría dentro del fuera de campo visual que no podemos encontrar en el ámbito pictórico, por lo que la influencia de ésta en su utilización será nula. Sin embargo, éste sí que será un recurso muy utilizado en el teatro y el cine heredará esta forma de introducir los personajes en la escena desde esa disciplina. Por tratarse de una obra esencialmente pictórico-teatral, y debido a la fiel utilización de la cámara fija, la obra de Méliès se encuentra plagada de entradas y salidas de campo. Como ejemplo cabe subrayar Prohibido fijar carteles (Defense d'Afficher, Georges Méliès, 1896) por ser el primer ejemplo del recurso en la obra del cineasta. Además, hay que recordar otros dos films donde la desaparición de los personajes se realiza de una forma poco habitual. El primero de ellos es Juana de arco (Jeanne d'Arc, George Méliès, 1990) en el que vemos cómo los personajes trepan por unas escaleras para desaparecer finalmente por el borde superior, muy poco utilizado para este tipo de recursos. El último ejemplo es quizá el más inaudito dentro de la extensa producción de Méliès: dentro de la serie de películas sobre El proceso Deyfus, encontramos El atentado contra el abogado Labori (Attentat contre maitre Labori, Georges Méliès, 1899), donde al comenzar la escena, los personajes entran desde el segmento correspondiente a la cámara, activando el espacio fuera de campo que correspondería con la posición del espectador, segmento muy poco utilizado para la aparición o desaparición de los personajes, siendo mucho más habitual la utilización de los segmentos laterales (F3, F4). 


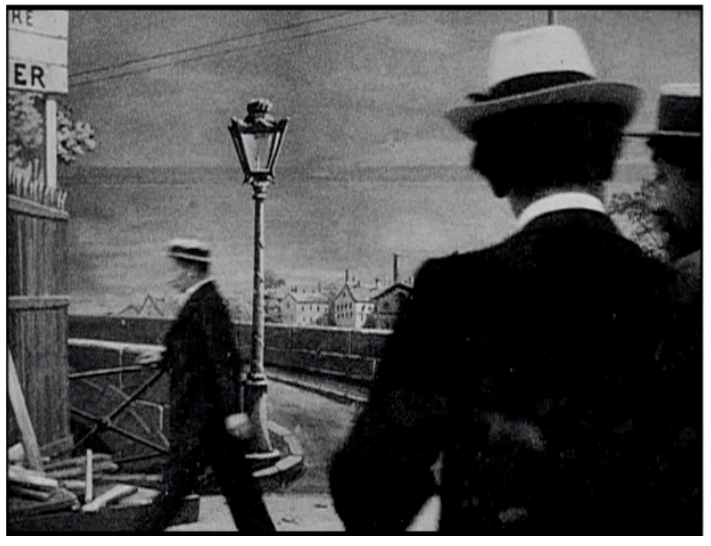

F3

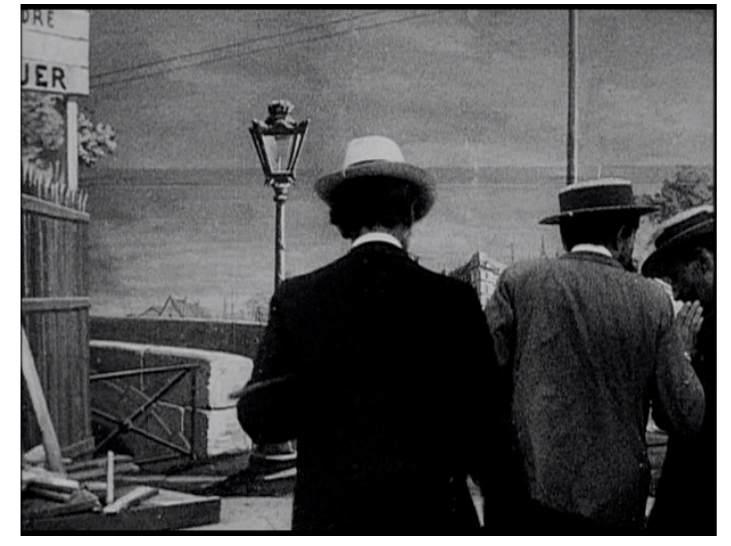

F4

La última categoría dentro del fuera de campo visual corresponde a los reencuadres mediante los cuales es posible convertir el campo en fuera de campo y viceversa. A través de este diálogo continuo entre ambos espacios, es posible dirigir la atención del espectador hacia aquello que, habiéndose mostrado en la pantalla, queda ahora oculto tras sus límites. Los reencuadres serán prácticamente inexistentes en los primeros años del cine, y su introducción se realizará de forma muy lenta. En cuando a la producción de Méliès, resultan muy reveladoras sus propias palabras:

[...]Qué decir de las filmaciones actuales, cuyo objetivo se supone que es seguir a personajes de la vida real y fotografiarlos sin que ellos se den cuenta...Qué decir también de los decorados que se desplazan horizontalmente, o de abajo arriba, para dejar ver las distintas partes de una habitación, de los personajes que súbitamente engordan, cuando no son sus manos y pies los que se vuelven enormes para dejar ver un detalle. Con toda evidencia nos dirán: ies la técnica moderna! ¿Es ésta la buena técnica? Este es el problema: ¿Es natural? (Méliès, 1930, p.84)

\section{Conclusiones}

Tras visualizar la extensa producción de Méliès, es inevitable guardar una concepción del cine de los orígenes como un método de representación 
esencialmente pictórico y teatral, con una utilización del espacio muy limitada e inconexa. En cierta medida, estas afirmaciones son ciertas, pero es importante recordar cómo estas primeras producciones cinematográficas abrieron el camino hacia un uso del fuera de campo que si en la pintura y el teatro comenzó a mostrar sus posibilidades, en los primeros años del cine empezará a consolidarse como parte esencial en toda representación espacial. El paso de las décadas proporcionará al fuera de campo innumerables posibilidades, convirtiendo el espacio en la pantalla en uno completamente ilimitado. Este hecho, hace olvidar a menudo el papel pionero del cine de los orígenes en la implantación del recurso, y es que las restricciones que ocasionaba el uso de la cámara fija, hacen pensar en un espacio centrípeto y totalmente cerrado en el que no se hacía referencia al espacio más allá de los límites de la pantalla. Nada más lejos de la realidad. Con ejemplos como El regador regado, Prohibido fijar carteles o Mary Jeane's mishap se puede comprobar como la falta de movimiento de la cámara no funciona sólo como limitador del espacio, sino que además, provoca la existencia de un fuera de campo inevitable al que se aludirá constantemente con recursos como las entradas y salidas de campo. Podría pensarse que con la implantación del Método de Representación Institucional, -que trajo consigo una mayor libertad espacial-, el fuera de campo fuese utilizado con mayor asiduidad, dadas las extensas posibilidades que adquirió con la incorporación del sonido, los movimientos de cámara y el montaje. Sin embargo, precisamente debido a la posibilidad que ahora ofrecía la pantalla para mostrarlo todo, el fuera de campo fue relegado a un segundo plano con la introducción de recursos como el campo-contracampo que se convirtieron en una norma durante el cine clásico. Podemos afirmar, por tanto, que el uso del fuera de campo fue más común durante los primeros años del cine que durante la posterior instauración del cine clásico. Habrá que esperar hasta el desarrollo del cine moderno para encontrarnos con una utilización del recurso mucho más extendida y diversa. Por su parte, la influencia pictórica en la pantalla será una constante hasta el cine de nuestros días, aunque las relaciones cine-pintura han cambiado de forma notable. Si antes los rasgos pictóricos en la construcción espacial del cine formaban parte de sus cimientos, siendo inconcebible una 
construcción espacial diferente, actualmente la utilización de rasgos pictóricos para representar el espacio son una elección consciente.

Con estas conclusiones, nuestro artículo se enmarca en las líneas defendidas por autores como Francisco Gómez Tarín en cuanto a la aparición temprana del fuera de campo en los primeros años del cine. No obstante, de nuestros estudios también deriva la concepción del fuera de campo como un recurso no sólo cinematográfico, sino también con presencia en el ámbito de la pintura. Esta es, quizá, la idea más discutida y contraria, curiosamente, a lo defendido por Francisco Gómez Tarín. A este respecto, nuestras ideas se alienan más con autores como Jacques Aumont o Pascal Bonitzer, que utiliza a Edward Hopper como el perfecto ejemplo de la presencia del fuera de campo en la pintura en su obra Desencuadres (Bonitzer, 2007). De tal forma, podríamos afirmar que lo defendido a lo largo de este artículo parte de las ideas desarrolladas por Gómez Tarín para, después, alinearse con aquellos autores que, a pesar de aceptar las limitaciones del recurso en esta disciplina, no dudan en aceptar la existencia de un fuera de campo pictórico que habría funcionado como antecedente de aquel que posteriormente se desarrollará y evolucionará en el seno del cine.

\section{Referencias bibliográficas}

Aumont, J. (1997). El ojo interminable. Cine y pintura. Buenos Aires: Paidós.

Bonitzer, P. (2007). Desencuadres. Cine y pintura. Buenos Aires: Santiago Marcos.

Burch, N. (2016). El tragaluz del infinito. Madrid: Cátedra.

Burch, N. (2008). Praxis del cine. Madrid: Fundamentos.

Deleuze, G. (1984) La imagen-movimiento. Barcelona: Paidós.

Durand, P. (1993). Cinéma et montage: un arte de l'ellipse. París: Éditions du Cherf.

Gómez Tarín, F. J. (2006). Más allá de las sombras. Lo ausente en el discurso fílmico desde los orígenes hasta el declive del clasicismo (1895-1949). Castellón: Universitat Jaume I.

Méliès, G. (1930). Les vues cinématographiques. Le Nouvel Art Cinématographique, 5 ( $2^{\mathrm{a}}$ serie). 
Sadoul, G. (1964). Louis Lumière. París: Seghers.

\section{Filmografía}

Griffith, David Wark (1915). The birth of a nation. EEUU: David W. Griffith Corp.

Kurosawa, Akira (1990). Dreams. Japón/EEUU: Warner Bros.

Lang, Fritz (1931). M. Alemania: Nero Film.

Lumière, Louis (1895). La sortie des usines Lumière. Francia: Lumière. (1895). L'arrivée d'un train en gare. Francia: Lumière.

(1895). L'arroseur arrossé. Francia: Lumière.

Majewski, Lech (2001). Mlyn I Krzyz. Polonia: Silesia Film.

Méliès, George (1896). Une partie des cartes. Francia: Star Film.

(1896). Defense d'Afficher. Francia: Star Film.

(1898). Panorama pris d'un train en marche. Francia: Star Film.

(1899). Cendrillon. Francia: Star Film.

(1899) Attentat contre maitre Labori. Francia: Star Film.

(1900) Jeanne d'Arc. Francia: Star Film.

(1901) L'homme a la tete en cahoutchouc. Francia: Star Film.

(1903) La boite a malice. Francia: Star Film.

Murnau, Friedrich Wilhelm (1922). Nosferatu. Alemania: Prana Film.

Smith, George Albert (1903). Mary Jane's Mishap. Inglaterra: G.A. Smith.

Rohmer, E (1976). Die Marquise von O. Alemania: Les filmes du Losange. 